\title{
Software Xlupa - um ampliador de tela para auXílio na educação de alunos COM BAIXA VISÃ $0^{1}$ \\ Xlupa Software - a screen magnifier to aid in educating Students With loW Vision
}

\author{
Jorge BIDARRA 2 \\ Clodis BOSCARIOLI ${ }^{3}$ \\ Sarajane Marques PERES ${ }^{4}$
}

RESUM 0: o modelo educacional brasileiro vem passando por muitas transformações. Partedelas está relacionada a, pelo menos, dois fatores: a necessidade deinclusão deal unos com necessidades especiais no sistema educacional e o uso dos computadores nos processos de ensino, como forma de potencializar os resultados da aprendizagem desses al unos. A pesar dos esforços real izados, tanto na questão da inclusão educacional quanto na informatização de atividades inerentes aos ambientes escolares, a grande dificuldade é saber como atender adequadamente a esses alunos que, atualmente, representam uma parcela significativa da população estudantil matriculada na rede de ensino pública e/ ou particular. Considerando que dentre esses alunos estão aqueles que, embora não sejam cegos, apresentam um significativo grau de redução na acuidade visual, denominados "Baixa Visão", e sabendo que o uso do computador tem aumentado nas escolas brasileiras, há fortes motivos para acreditar quea lacuna hoje existente na formação desses indivíduos pode ser minimizada mediante a adequação de recursos computacionais ao processo de aprendizagem. Neste artigo, é apresentada a ferramenta computacional denominada xLupa, um ampliador de imagens e textos em telas de computador para alunos com baixa visão. Para tanto, os tópicos abordados nesse artigo são os seguintes: Descrição da especificação e desenvolvimento da ferramenta, o que envolveu um estudo das necessidades visuais do público alvo, bem como a interação contínua de desenvolvedores e usuários; A presentação do software xLupa e de suas funcionalidades; e uma avaliação sobre como o seu uso pode auxiliar alunos e professores no dia-a-dia escolar.

PALA VRAS-CHAVE: Alunos com Necessidades Especiais. Deficiente da Visão. Recursos Ópticos.

A BSTRACT : The Brazilian education model has undergone many transformations. Some of these are related to at least two factors: the need for including students with special needs in the educational system, and the use of computers in learning-teaching processes in order to enhance such students' learning outcomes. Despite the efforts applied to both the issue of educational inclusion and to promoting computer access to educational activities in school environments, the major difficulty is how to adequately serve those students who currently represent a significant portion of the population enrolled in public, or private, school systems. Among the special needs students, there are those with a significant degree of reduction in visual acuity, called "Low Vision". Knowing that the use of computers in Brazilian schools has increased, there are strong reasons to believe that the gap currently inherent in the education of these individuals may be minimized by promoting

\footnotetext{
${ }^{1}$ Agradecimentos: Ao CNPq e aos colaboradores do projeto, em especial aos alunos com baixa visão e seus professores, bem como a todos os acadêmicos que atuam ou já atuaram no Projeto.

${ }^{2}$ Doutor em Linguística Computacional (UNICAMP). Universidade Estadual do Oestedo Paraná - UN IOESTE, Campus de Cascavel. Departamento de Ciência da Computação e Núcleo de Inovações Tecnológicas. jbidarra@unioeste.br ejbidarra@pq.cnpq.br

${ }^{3}$ Doutor em Engenharia Elétrica (USP). Universidade Estadual do Oeste do Paraná, UNIOESTE. Campus de Cascavel Departamento de Ciência da Computação. boscarioli@unioeste.br

${ }^{4}$ Doutora em Engenharia Elétrica (UNICAMP). Universidade de São Paulo - USP. Escola de Artes, Ciências e Humanidades. sarajane@usp.br
} 
access to computer resources in the learning-teaching process. In this paper, we describe the computer tool called XLupa, a screen magnifier, applied to images and texts, for students with low vision. To this end, the topics covered in this paper are: a) description of thetool specification and development process, which involved a study of the target users' visual needs, and the continuous interaction between developers and users, b) presentation of XLupa and its functionalities; c) assessment of how its use can help students and teachers in daily school activities.

KEYWORDS: Special Education. Digital Accessibility. Low Vision. Technology and Education. Equipment for Special Education.

\section{INTRODUÇÃo}

De acordo com o censo publicado em 2000 pelo IBGE, 14,5\% da população brasileira sofre de algum tipo de deficiência motora, mental ou visual. Desses, estima-se quemais de $60 \%$ são deficientes visuais, distribuídos entre cegos ou de baixa visão ${ }^{5}$ Se a cifra no geral já é considerada alarmante, mais crítica fica ao seconsiderar que uma parte significativa de toda essa população está em idade escol $\mathrm{r}^{6}$. Essa situação se agrava cada vez mais, tendo em vista que são al unos de diferentes idades e níveis e que, com raras exceções, recebem um atendimento adequado por parte das instituições de ensino em que estão matriculados. 0 resultado desse, por assim dizer, "abandono" não poderia ser outro senão a evasão escolar; algo provocado pela total falta de motivação, não só por parte do aluno, mas também dos educadores/ professores e pais que, sem condições de trabal ho e não sabendo o que fazer em muitos casos, não vislumbram qualquer perspectiva de propiciar a essas crianças, jovens e adultos o acesso ao conhecimento a quetêm direito, como apregoam as Leis dos Direitos Humanos constantes em tratados nacionais e internacionais.

Um dos grandes desafios atuais colocados para as sociedades modernas estájustamenteem encontrar soluções para os problemas enfrentados pelas pessoas com limitações físicas e/ ou mentais. Vários estudos têm sido realizados no sentido de identificar e desenvolver soluções eficientes e acessíveis para essas pessoas, dentre os quais, podendo-se citar, Souza et al. (1999); Santarosa e Martins (1995); Charin e Capovilla (2000); Koon eV ega (2000); Santarosa (2000). O mesmo também acontecendo no âmbito dos investimentos governamentais, com políticas sociaise

\footnotetext{
${ }^{5}$ N.T.: Considera-se Baixa Visão todo indivíduo que somente a uma distância de 20 pés (aproximadamente $6,096 \mathrm{~m}$ ) será capaz de enxergar uma mesma imagem que uma pessoa com visão normal enxergaria a 200 pés ou $60,96 \mathrm{~m}$ (COLEMBRANDER, 2000).

${ }^{6}$ De acordo com documento com dados referentes ao período de 1998 ao ano de 2006 publicado pela Secretaria deEducação Especial - SEESP (http:/ / portal.mec.gov.br/ index.php?option=com_content\&view=article\&id= 12507\&Itemid=826 - acesso em 22/ 07/ 2010), um setor vinculado ao Ministério da Educação, o número de matrículas que em 1998 era de 337.326 alunos, atingiu a marca de 700.624 alunos, um acréscimo de 107\%. Dessas matrículas, consideradas apenas no ano de 2006, 375.488 foram realizadas em escolas especializadas e em classes especiais, contra 325.136 em escolas regulares/ classes comuns. O maior contingente situava-se em escolas públicas (63\%) e 37\%, em escolas privadas, com a sua grande maioria (466.155) matriculada na educação fundamental, correspondendo a 66,5\% do total, seguido de 112.988 (16\%), na educação infantil; 58.420 (8,3\%), na educação de jovens e adultos; 48.911 (6,3\%), na educação profissional; 14.150 (2\%), no ensino médio. Relativamente ao ensino superior, o mesmo documento registra que, entre de 2003 a 2005, a quantidade de alunos especiais matriculados saltou de 5.078 para 11.999, um aumento de $136 \%$.
} 
educacionais, a exemplo do PROINESP (Projeto de Informática na Educação Especial $^{7}$ ). As tecnologias de uma maneira geral, eem particular as computacionais assistivas, têm sido, nesse contexto, uma fonte de referências e motivações (HOGETOP; SANTAROSA, 2002).

No Brasil e no mundo, vem-se desenvolvendo lenta, mas progressivamente, comportamentos eatitudes positivas em relação às pessoas com deficiências. Os avanços perpetrados em suas tentativas são facilmenteverificados, bastando para tanto ver a sequência histórica que tem o seu início marcado pelo total abandono desses indivíduos à própria sorte, assumindo, mais adiante, contornos caritativos, segregacionistas e assistencialistas, para, nos dias de hoje, culminar, como se refere Bueno (1993), em ações inclusivas, um novo paradigma que assume como premissa básica descobrir meios que possam facilitar o acesso de todos, indistintamente, ao conhecimento.

Contudo, num ambientetão complexo como éo das relações humanas, nas quais estão em jogo pessoas com habilidades mais ou menos desenvolvidas e distintas, à primeira vista, poderia parecer muito difícil emesmo quase impossível garantir-Ihes as mesmas condições de acesso ao conhecimento, especialmente quando sofrem algum tipo de limitação.

No variado conjunto das deficiências hoje catalogadas pelos órgãos nacionais e internacionais de saúde, uma delas em específico é destacada neste texto: a baixa visão. Enquanto oficialmente reconhecida como uma importante variação da deficiência visual, curioso é notar que, por mais paradoxal que possa parecer, trata-se de uma patologia que, se não totalmente, mas em grande parte, tornou-se invisível para a sociedade de uma maneira geral: porque enxergam, não importando o grau das suas acuidades visuais, o mais comum équesejam tomadas por pessoas videntes. Um erro não apenas de um ponto de vista biológico, mas, além disso, de grande perversidade. Quando assim rotuladas, não raro, essas pessoas tornam-se vítimas fáceis de um sistema, que em não as reconhecendo em suas necessidades, passa-Ihes cobrar e submetêlas a desafios para os quais não estão preparadas ou não dispõem de condições que lhes permitam superar os obstáculos apresentados.

A pior consequência disso équeenquanto para essa sociedadeesistema a dimensão do problema dos indivíduos baixa visão continua passando ao largo, para as muitas escolas, notadamente as públicas, que recebem esses alunos, o problema assume dimensões el evadas, não apenas para as instituições (direções, professores efuncionários), mas também para os estudantes esuas próprias famílias. Em tais circunstâncias, não há outra saída senão buscar caminhos que possam de al gum modo socorrer a todos - alunos, educadores e familiares - nesse complexo processo estabelecido entre ensino e aprendizagem.

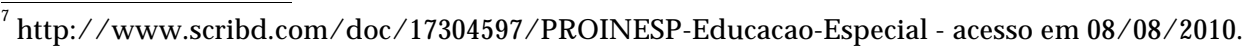


Proporcionar à pessoa com deficiência maior independência, qualidade devida einclusão social, seja pela ampliação da comunicação, mobilidade, controle do seu ambiente, ou para o desenvol vimento desuas habilidades deaprendizagem, competição, trabal ho eintegração com a família, amigos esociedades, éo principal objetivo da Tecnologia A ssistiva (doravante, apenas referida pela siglaTA), também chamada de Ajudas Técnicas (BERSCH; TONOLLI, 2009). Quando aplicadas ao ambiente educacional, o uso dessas tecnologias, especialmente se mediadas por computador, tende oferecer ao aluno com deficiência não apenas melhores condições de aprendizagem, como também funcionar como um incentivo à sua maior partici pação e integração junto aos demais colegas de turma e professores. Conforme Santarosa (1997), a importância que essas tecnologias assumem no ambiente educacional, notadamente para o caso de alunos com necessidades especiais, não é apenas uma realidade, mas um componente auxiliar de destaque na relação estabel ecida entre o ensino e a aprendizagem.

Com efeito, o aluno com deficiência é aquele que para evoluir em seus estudos depende de instrumentos especificamente construídos para as suas necessidades. Assim acontece, por exemplo, com as pessoas com Deficiência Visual (DV), Deficiência Auditiva (DA) e com Paralisia Cerebral (PC). Mas, se por um lado não restam dúvidas dequeos recursos pedagógicos adaptados são importantes no processo educacional desses alunos; por outro, éabsolutamente necessário que haja clareza por parte de todos e dos educadores em particular sobre a concepção que se deve ter de pessoa com deficiência, pois é justamente essa compreensão que precisa ser tomada como parâmetro para dar os encaminhamentos metodológicos adequados às demandas impostas.

A Escola é uma peça fundamental em todo esse processo. Cabe a ela prover a transmissão do conhecimento de forma sistematizada, a partir da qual são criadas as condições para queo al uno desenvolva as suas potencialidades sociais ecognitivas, quelheserão úteis ao longo detoda a sua vida. Além das metodologias pedagógicas tradicionais, as tecnologias educacionais constituem, assim, um importante recurso a serviço e ao alcance dos professores e também dos alunos.

Denomina-se TA, segundo Cook, Polgar e Hussey (1995), o conjunto de Recursos e Serviços disponíveis para auxílio às pessoas, conforme as necessidades estabelecidas. Os Recursos, no conjunto das definições aplicáveis, são itens, equipamentos ou parte deles, produtos ou sistemas fabricados em série ou sob medida, utilizados para aumentar, manter ou melhorar as capacidades funcionais das pessoas com deficiência. Os Serviços são os meios que auxiliam diretamente uma pessoa, particularmente, mas não restritivamente, aquelas com deficiência em atividades quotidianas, tais como selecionar, comprar ou usar os recursos acima citados. Esses serviços são, normalmente, transdisciplinares, envolvendo profissionais de diversas áreas, dentre elas a Fisioterapia, Terapia Ocupacional, Fonoaudiologia, Educação, Psicologia, Enfermagem, Medicina, Engenharia, A rquitetura e Ciência da Computação. 
Tanto os recursos quanto os serviços precisam ser planejados e projetados conforme as necessidades específicas dos indivíduos. Logo, o que poderia ser adequado para os PC, pode não ter qualquer aplicabilidade para o DV ou para o DA. Portanto, para deficiências específicas, necessita-se de soluções igualmente específicas.

A visão humana, senão o principal, com toda certeza é um dos mais importantes sentidos. Por meio dela, somos capazes de reconhecer o universo e assim a ele nos adaptar com mais facilidade. No dia-a-dia, seja em nossas casas, no trabal ho, na escola ou no lazer, grande parte da nossa interação com o universo depende da visão. Embora muitas vezes não tenhamos consciência disso, o mundo que se nos apresenta parece apenas explicável se por meio da visão. Esse é, afinal, o modelo que nós mesmos construímos e acreditamos.

Para os DVs, sob esse ponto de vista, o mundo parece se tornar menos acessível, pouco amistoso e cheio de desafios para serem transpostos. Diferentemente dos cegos, no entanto, as pessoas com baixa visão são muitas vezes invisíveis aos ol hos da sociedade. Talvez porqueainda contem com al gum resíduo visual, é muito frequente serem consideradas como videntes. Mas o que não é considerado é que esse resíduo, na grande maioria dos casos, não Ihes permite o acesso às imagens e aos textos que eventual mente precisarão ler ou visualizar.

A s escolas, embora preocupadas com os alunos com deficiência visual, parecem não se dar conta de que os al unos com baixa visão também necessitam de um atendimento especial. Se colocados à margem, por si mesmos, não lograrão o êxito desejado pelas escolas, seus professores, responsáveis e por eles próprios, com toda a certeza.

Há muitas maneiras de os problemas das pessoas com baixa visão poderem ser contornados. Uma das possibilidades seria pela mediação de computadores, por meio dos chamados ampliadores de telas. É nesse ambiente e com uma preocupação de cunho educacional que tem início o desenvolvimento e o uso da ferramenta xLupa (BIDARRA; BOSCARIOLI; RIZZI, 2009). Trata-se de um softwarelivrecuja principal funcionalidadeéampliar textos eimagens exibidas em telas de computador, um recurso computacional básico e necessário para o bom aproveitamento escolar de alunos com baixa visão.

\section{SoftWARE XLUPA}

O projeto XLupa surgiu da constatação, pelo convívio no interior da universidade e também com a comunidade educacional externa, de que a problemática queenvolveosalunos com deficiência visual, notadamenteos de baixa visão, exigia uma solução urgente que pudesse ser útil não apenas para os alunos, mas também um instrumento de auxílio para os professores em suas atividades pedagógicas. Muito marcante nas falas dos educadores, durante as reuniões de trabalho com o grupo de desenvolvimento do xLupa, é que a falta de um de um 
programa de atendimento efetivo, seja por parte do governo ou pelas próprias instituições de ensino, estava (e ainda está) tornando praticamente inviável a condução de um trabalho eficientee eficaz com al unos nessa condição. Não obstante essa realidade, outro aspecto também estava no centro das preocupações desses professores. Para eles, muito pouco seria possível se aos programas, mesmo que existindo, não se juntassem as famílias, as instituições de pesquisa e a sociedade, de um modo geral. N essecontexto, inaugurou-seesse novo projeto. Mas, o que, em sua primeira concepção, seria um trabal ho denatureza puramentecomputacional , a partir dessas reflexões passou a assumir contornos mais especificamente de natureza educacional no âmbito da inclusão dealunos com baixa visão.

Com o advento do computador, os recursos tecnológi cos educacionais começaram, a pouco e pouco, se definir como um forte aliado dos professores no processo de formação dos alunos. Sebem explorados, tanto os professores quanto os alunos tornam-se cada vez beneficiários das soluções existentes, tanto mais evidente se esses recursos puderem ser explorados por al unos com necessidades educacionais especiais.

O xLupa, enquadrado na categoria TA, mais especificamente um ampliador de tela para pessoas com baixa visão, embora não exatamente um software educacional, vem sendo utilizado por professores especializados das escolas parceiras do projeto como ferramenta deauxílio para al unos nessa condição, cujos resultados obtidos até o momento vêm se mostrando bastante animadores.

O objetivo aqui não é exatamente apresentar um relato dos resultados obtidos com o uso da ferramenta, mas apresentar um pouco da trajetória da pesquisa ao longo de seu desenvolvimento, a começar pelos requisitos considerados relevantes para a construção do software.

Como ampliador detela, convém lembrar, o xLupa não difereem muito de outros ampliadores disponíveis para uso. Contudo, ao assumir a condição de instrumento com propósitos não apenas de cunho geral, mas voltada para uma aplicação educacional, os requisitos exigidos para a sua concepção forçaram a adoção de uma linha de raciocínio mais criteriosa. Mais do que apenas ampliar, a equipe precisou considerar elementos que pudessem imprimir à ferramenta um funcionamento mais amigável, confortável e, de certo modo, lúdico para o usuário na sua interação.

Deum modo geral, as pessoas com baixa visão, mesmo com o material deacesso ampliado adequadamente, são suscetíveis à fadiga, que, no caso específico dos computadores, seriam provocadas pela forte exposi ção a queficam submetidas aos rai os catódicos emitidos pelos monitores. Esses cansaços frequentes, plenamente justificados, além de prejudiciais, segundo especialistas, acabam respondendo pelo alto grau de desistência desses indivíduos às atividades de estimulação visual prescritos pelos oftalmologistas e, no caso do ambiente educacional, conduzidas por professores especializados na área da deficiência visual. 
Em muitas situações, o problema da fadiga está mais diretamente relacionado à, como já mencionado, emissão desses raios. Porém, associados a isso, entram em cena fatores, tais como o tamanho da fonte das letras, o impacto das cores e a luminosidade das projeções. Essas seriam ainda variáveis de natureza mais técnica. Segundo Paschoal (1993), a pessoa com baixa visão possui dificuldades que incluem a localização e a qualidade da identificação das imagens no espaço. Muitas vezes, para essas pessoas, a formação de conceitos que necessitam da imagem visual para uma boa compreensão encontra-se bastante prejudicada.

No geral, a baixa visão envolve sintomas que podem ir do escurecimento da visão à sensibilidade anormal à luz ou claridade, passando por visões embaçadas, capacidade visual apenas para objetos colocados muito próximo do observador, visão tubular ou, num outro extremo, periférica (o indivíduo apenas enxerga as bordas das imagens, ao contrário do caso anterior, em que somente é vista a parte central da imagem, como se ol hada através de um tubo), cegueira noturna, até distorção das cores ou, em al guns casos, com sintomas de daltonismo (VANDERHEIDEN; VANDERHEIDEN, 1991).

No conjunto de todos esses problemas, um deles merece particular atenção: a questão da distorção das cores. De acordo com Guimarães (2003), a cor é um dos mais importantes mediadores que atuam no processamento mental humano. Através das cores, são estabelecidas relações que possibilitam aos indivíduos uma compreensão e uma comunicação mais efetiva, que tanto podem englobar processos organizacionais, chamadas de atenção ou áreas de destaques, criações de planos de percepção, ambientação, quanto atribuição de significados às coisas (LAWRENCE; VANDERHEIDEN, 1998). Jacobson e Bender (1996), ao discutirem as cores, vão dizer, inclusive, que as cores, as quais classificam como frias ou quentes, podem ser mais ou menos atraentes, transmitindo uma sensação de proximidade ("cores quentes") ou distanciamento ("cores frias") de objetos em relação ao observador, o que, para o caso específico dos baixa visão, podeproduzir um efeito desejado ou não, dependendo da situação.

Com base nos estudos realizados sobre a influência das cores sobre os indivíduos baixa visão, o grupo de desenvolvimento do xLupa concluiu que a exploração do recurso constituiria um requisito de fundamental importância. Assim, foi implementado um sistema de seleção de cores, em princípio, bastante simples, com a apresentação para o usuário de uma tela contendo uma palheta de cores (vermel ho, azul, verde, preto e branco), a partir da qual é escolhida aquela que seja do seu agrado; cor essa aplicada como fundo da imagem ampliada. Já a cor da fonte, uma vez definida a cor de fundo, obtém-se por meio de um tópico de menu interno, contendo o mesmo padrão decores da palheta inicial. Dessa forma, o sistema propicia ao usuário a possibilidade de combinar duas cores, uma de fundo e outra de frente, com o contraste adequado as suas necessidades.

O tratamento das coresé, defato, um capítulo à partena implementação do xLupa; mas claro não o único item a ser considerado. Dentre os outros requisitos, 
encontram-se ainda a necessidade de tratamento dos contornos das imagens, luminosidade, definição do tipo de cursor, recurso de leitura de tela e, como um grandediferencial em relação aos outros ampliadores, a capacidadederastreamento e salvamento do perfil do usuário ao longo de uma sessão de trabalho com a ferramenta.

No tocante ao contorno das imagens, duas soluções estavam em jogo. Uma delas, apenas ampliar a imagem sem qualquer tratamento específico, o que, dependendo do fator de ampliação adotado, acaba por gerar um efeito indesejado deserrilhamento da imagem; isto é, os fragmentos queservem para dar os contornos à imagem, ao serem conectados, não formam uma linha contínua, mas linhas "dentadas" (entre o final de um fragmento e o início do outro surge um desnível). Para resolver esse problema, a idéia seria arredondar os contornos, minimizando esse efeito; o que acabou resultando numa exibição, à primeira vista, mai s atrativa.

Muitas pessoas com baixa visão têm sérios problemas com ambientes claros ou com muita luminosidade. São pessoas com fotofobia. No caso do ampliador, uma forma deresolver o problemaépela redução do brilho nas imagens, um resultado conseguido com base na manipulação de atributos específicos associados aos pixels, unidades mínimas e constituintes dos monitores que, em conjunto, são os formadores das imagens exibidas nos monitores. Para estender o recurso mais efetivo, decidiu-se pela implementação de duas barras graduadas, uma para a intensidade do brilho e outra, para a cor, sobre as quais, movimentado o cursor para a esquerda ou para a direita, tanto a intensi dade do bril ho quanto do contraste podem ser reduzidas ou intensificadas, conforme a necessidade (Figura 1 - imagem à esquerda sem ampliação. Porção ampliada à direita).

Figura 1 - Menu para alteração de brilho e contraste

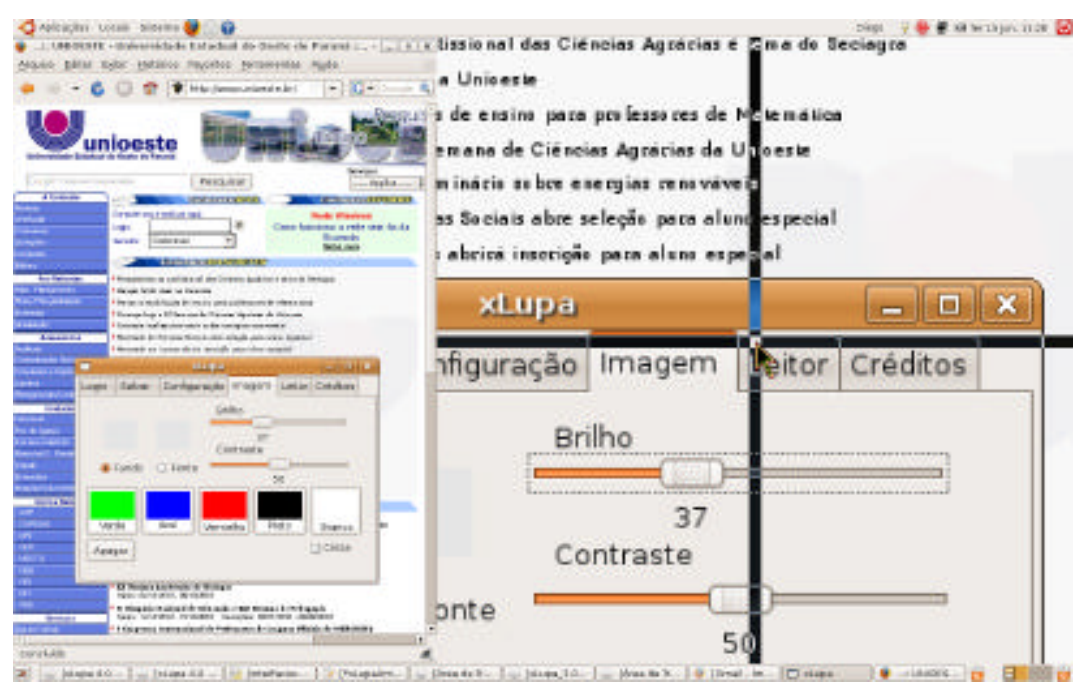

Fonte: elaboração própria. 
Para atender aos diferentes tipos de usuários, foram analisadas duas formas diferenciadas de cursores, em formato ponteiro e em cruz (Figuras $2 a$ porção ampliada à direita e $2 b$ - porção ampliada no topo da tela, respectivamente), incluindo-senão só a possibilidade deserem móveis ou fixados numa determinada posição da tela, mas também, para o caso de cursor em cruz, com possi bilidade de espessamento das linhas que se cruzam para a sua formação. A solução vem ao encontro das demandas dos próprios usuários, pois muitos deles apenas conseguem trabal har com cursor em cruz, para uns mais finos, para outros, mais espessos, o que os ajuda a manter o foco: dessa maneira, não se perdem em rel ação à imagem observada. Para outros, o fato de o cursor ser móvel, tanto faz se em cruz ou em ponteiro, éum problema; o que os faz preferirem a sua fixação no centro da tela da área de ampliação.

Figura 2 - Cursor em formatos diferentes. Em (a), formato Ponteiro; em (b) no formato de Cruz

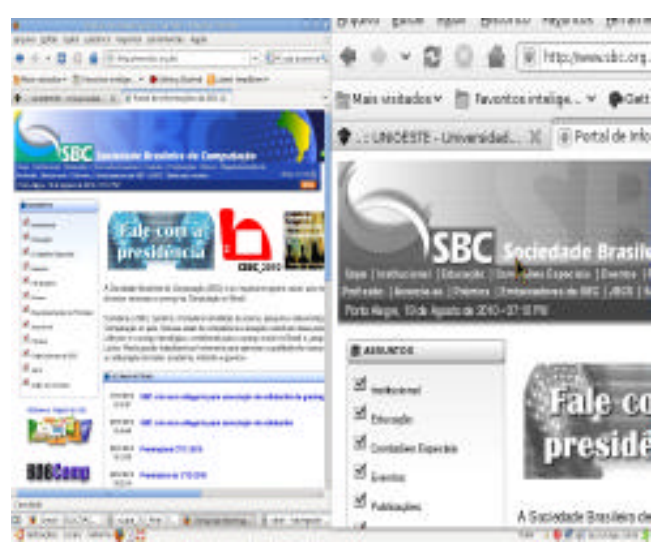

(a)

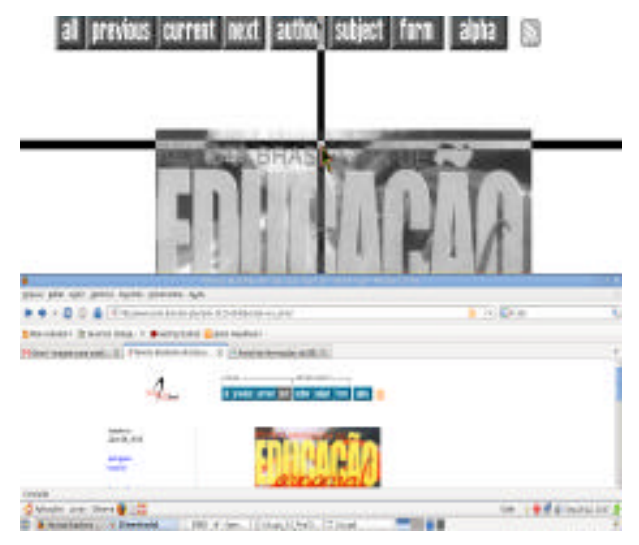

(b)

Fonte: elaboração própria.

Em princípio, não era objetivo no projeto implementar o xLupa com capacidade para leitura de tela. Contudo, mediante solicitações, esse requisito também foi considerado (Figura 3). A leitura, inicialmente sofreu uma resistência da equipe, dado que se temia o risco de que o ampliador perdesse a sua essência. Porém, compreendeu-se, enfim, que, para as pessoas com baixa visão, a leitura funciona como uma al ternativa de trabalho. Por meio da ampliação, com alternâncias deleitura detela pelo sistema, um dos principais causadores da fadiga, o esforço que precisariam fazer para a leitura, pode ser minimizado. Dependendo do trabal ho a ser executado e do grau de comprometimento da acuidade visual de cada um, as atividades, além de exaustivas, tendem provocar mal estar tais como enjoos, tonteiras e cefal eias, fazendo com que o seu tempo de permanência diante de um computador seja significativamente menor, se comparado aos videntes. 
Figura 3 - Menu para acionamento da leitura de tela

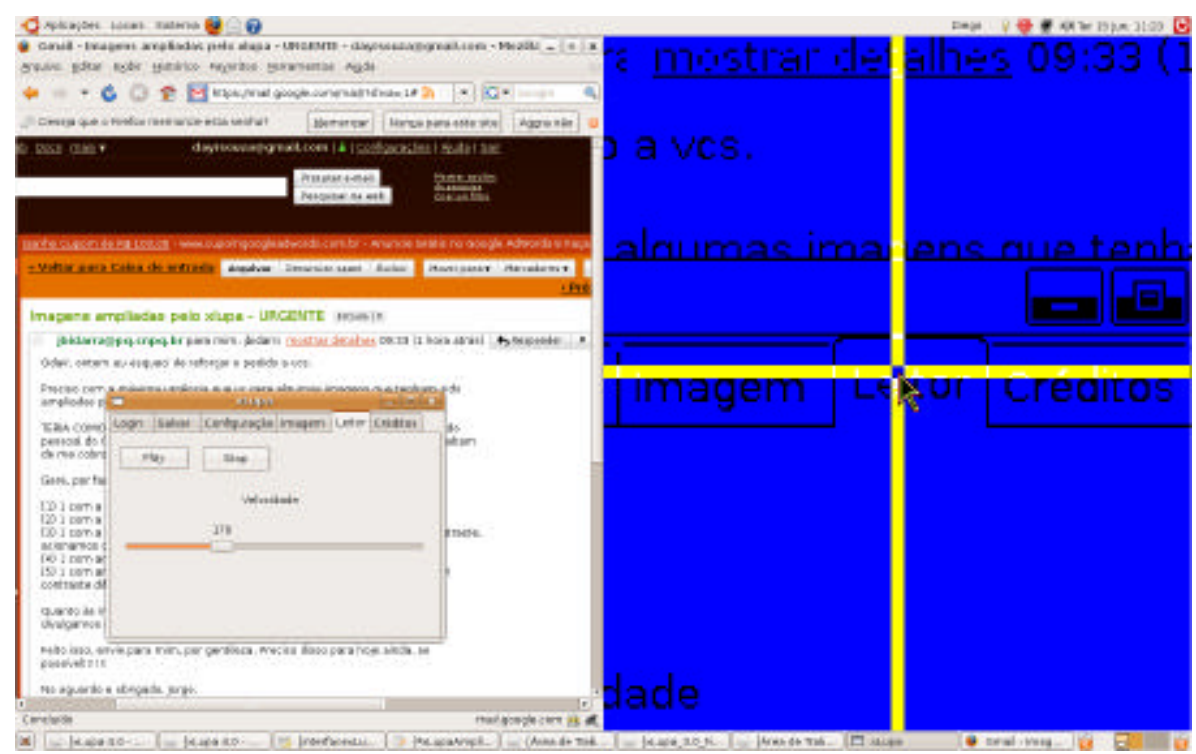

Fonte: elaboração própria.

Assim como o tratamento do contraste, a possibilidade de o usuário poder salvar configurações da área de trabalho com a ferramenta mostra-se um requisito importante. Para as pessoas com baixa visão, o recurso significa a eliminação de atividades repetitivas e, por consequência, com a redução do grau de fadiga a que estão sujeitos. O xLupa conta esse benefício, através do armazenamento e gerenciamento de perfis de usuário (Figura 4).

Figura 4 - Menu para acionamento do gerenciamento de perfis de usuários

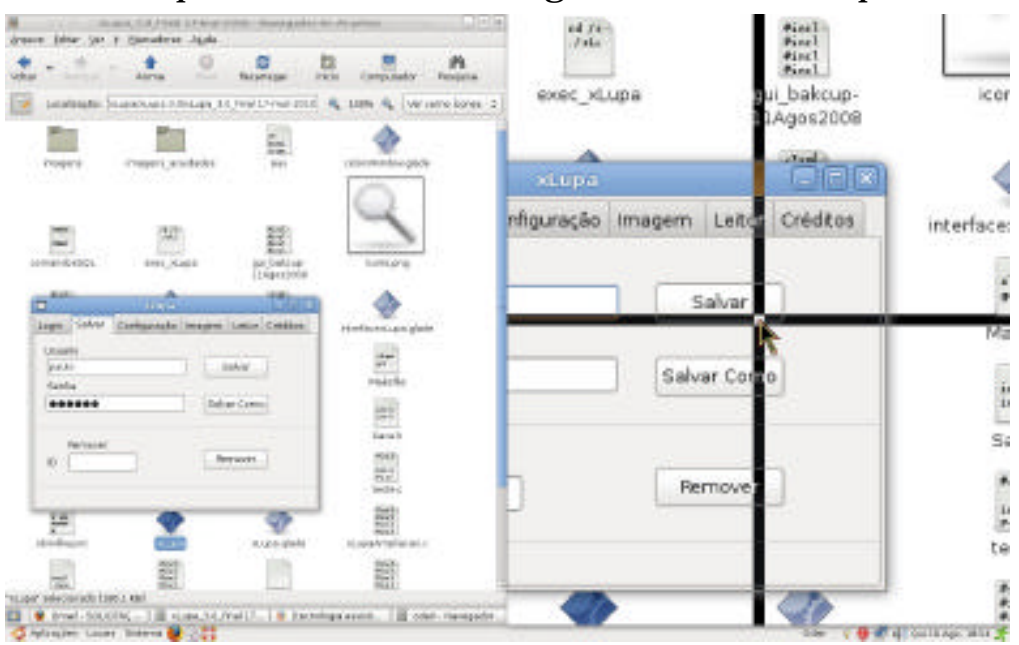

Fonte: elaboração própria. 
O xLupa é capaz de proporcionar a ampliação da informação visual presente em uma região da tela do computador. Esta região é capturada com rastreamento de mouse. A ferramenta permite que o usuário controle o nível da ampliação desejada ea taxa de tela útil a ser usada para a ampliação, atendendo ao exposto anteriormentesobrea necessidade deconsiderar o al cance ou a intensidade da deficiência de cada indivíduo, como ressal tado por RODNEY (2003). Na atual versão, as ampliações podem acontecer em áreas da tela que variam de $20 \%$ a $60 \%$ do espaço útil do monitor, na margem direita ou então no topo da tela (uma nova versão do xLupa para ampliação em tela cheia encontra-se em fase de testes).

A o ser ativado o xLupa, as imagens (figuras e textos) em suas formas originais passam pelo processo de ampliação, sobre as quais são aplicados al guns parâmetros de configuração. Inicial mente, dois parâmetros são levados em conta pelo sistema, cujos valores são determinados pelo usuário: o fator de ampliação e a cor de fundo, da seguinte maneira. Para a fixação (parâmetro com valor inicial) do fator de ampliação, apresenta-se para o usuário uma primeira tela contendo a palavra "XLupa" repetida, por linha edecima para baixo, em diferentestamanhos, conforme ilustração na Figura 5. Com base no que for sel ecionado pel o usuário, o que é feito por meio de um clique sobre a palavra desejada, o sistema captura o fator de ampliação que será usado para a ampliação.

Figura 5 - Tela inicial para sel eção do fator de ampliação

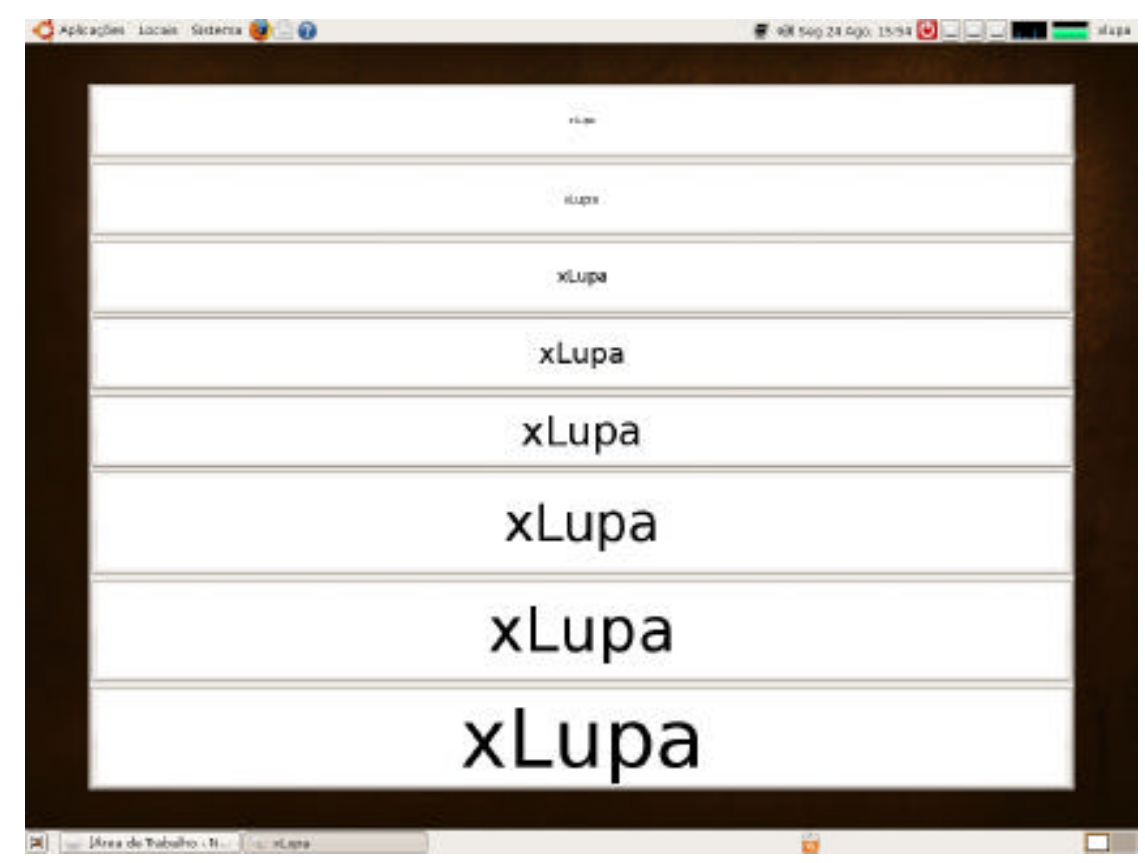

Fonte: elaboração própria. 
A bre-se, então, outra janela, agora contendo uma pal eta de cores, como mostrada na Figura 6. A cor selecionada pelo usuário, também mediante um clique sobre a mesma, será tomada como cor de fundo, cujo contraste será cal culado pelo próprio sistema, para efeito de exibição.

Figura 6 - Tela inicial para seleção da cor de fundo

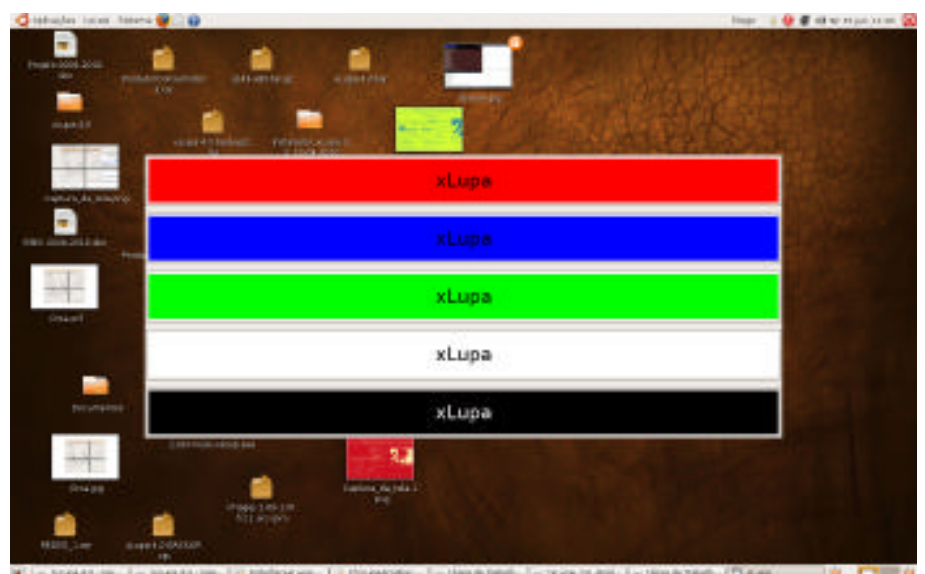

Fonte: elaboração própria.

A partir desse momento, o xLupa dá início às ampliações por meio da exibição de uma nova janela, contendo tópicos de menu, que se mantém ativada para o usuário durante toda a sessão de trabalho. A Figura 7 mostra, na parte superior da imagem, o resultado de uma ação típica de navegação web, na qual a ampliação da imagem é apresentada na parte superior da tela, com o brilho esfumaçado.

Figura 7 - Exemplo de uma ampliação com a imagem ofuscada

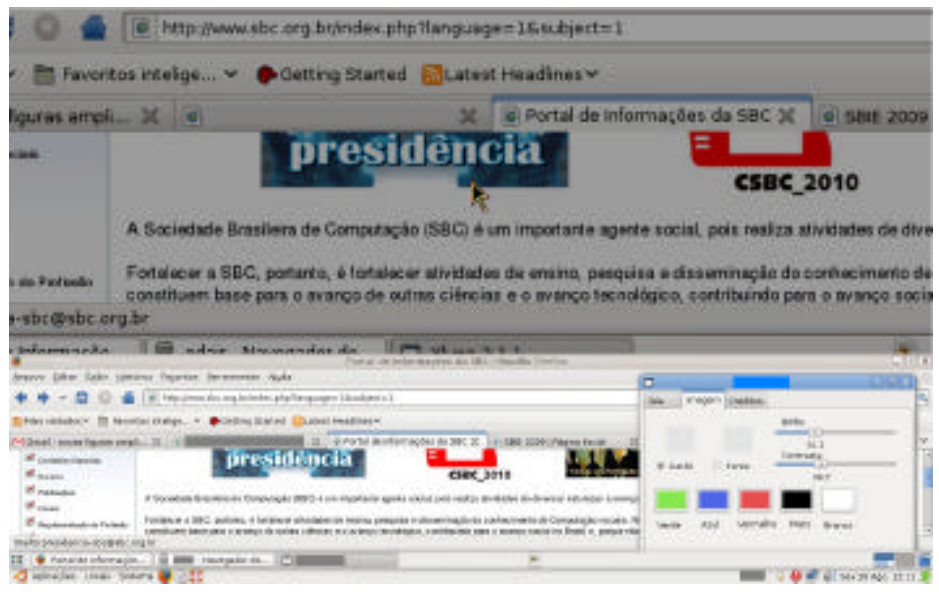

Fonte: elaboração própria. 


\section{Avaliação do ampliador de tela xLupa}

Essa seção é dedicada à avaliação do ampliador de tela xLupa. N ela, apresentamos as estratégias adotadas para aval iação, os diagnósticos eos principais resultados obtidos.

Não é demais lembrar que, embora o xLupa não seja uma ferramenta de uso exclusivo para al unos com baixa visão, o seu processo de desenvolvimento sempre esteve focado no universo escolar. Essa decisão permitiu estabelecer um ambiente controlado, não só útil para o desenvolvimento da ferramenta, como também para a sua aval iação, tanto por parte da equipe de desenvol vimento como também pelos especialistas em educação especial. Dentre outras vantagens, com tal estratégia a equipe pode assegurar melhores condições de observação (obter diagnósticos) e a efetiva consequência do uso da ferramenta como um software assistivo educacional, que serviram de base para as avaliações, o que fora feito a partir das respostas recebidas dos alunos, relativamenteàs facilidades/ dificuldades de uso, sugestões e queixas.

Para sustentar o processo de avaliação, foram formuladas baterias de testes. Esses testes, desdeo início, tinham por prioridade geral atacar duas frentes, uma com o foco nos aspectos de implementação e a outra, com base no usuário. No querespeita ao primeiro caso, foram consideradas duas métricas deEngenharia deSoftware para observação principal, a saber: corretudeecompletude decodificação. Com isso, buscou-se garantir não apenas a eficiência e a eficácia de execução da ferramenta, como também evitar situações frustrantes para o usuário. Com relação aos testes focados nos usuários (no presente caso, al unos com baixa visão) optouse pela distribuição dos testes em duas etapas. A primeira del as correspondeu aos testes realizados no laboratório de desenvolvimento. A segunda, na base escolar dos alunos participantes ${ }^{8}$. N esse último caso, para que os testes pudessem ser levados a bom termo, o projeto transferiu, a título de empréstimo e para uso exclusivo, recursos computacionais para as duas escolas públicas envolvidas, uma municipal e outra estadual ${ }^{9}$. A condução dos testes segue assim resumida.

Os critérios adotados para a seleção dos alunos tiveram por princípio garantir uma avaliação principalmente qualitativa, e não tanto quantitativa, até como forma de garantir a não exposição dos alunos a qualquer tipo de risco que pudesseadvir de um trabal ho não recomendável à idadee deficiência de cada um.

O primeiro critério foi que todos os alunos estivessem matriculados em escolas públicas. A motivação para esta escolha foi a preocupação em conduzir a pesquisa alinhada a uma perspectiva de fato inclusiva e acessível aos menos favorecidos, atendendo assim às condições delineadas junto aos apoiadores do

\footnotetext{
${ }^{8}$ Para cada fase de testes, um conjunto diferente, mas não disjunto, de alunos foi escolhido. Este foi um arranjo de caráter apenas circunstancial, ocasionado por limitações externas ao projeto e que incluem a logística, bem como a disponibilidade de horários dos alunos participantes.

${ }^{9}$ Esses empréstimos foram autorizados, tanto pelo CN Pq quanto pela Universidade ondeo projeto é executado. 
projeto. O segundo critério foi admitir apenas os alunos que portassem uma autorização de seus pais ou responsáveis diretos. Este critério visou garantir que não somente os alunos mais vel hos, mas também os menores de idade pudessem participar das atividades deavaliação. Alunos que, por ventura, não apresentassem essa autorização com antecedência eram retirados do processo ${ }^{10}$. O terceiro critério dizia respeito à apresentação de um laudo oftal mológico atestando a condição visual do aluno. A esse estado, devia juntar-se uma autorização expressa do médico liberando o al uno para participar dos testes.

Importa comentar aqui que a exigência de apresentação dos laudos médicos revel ou um dado importantee uma inquietude, qual seja, a grandemaioria dos alunos ou não tinham esses laudos ou, se tinham, estavam desatualizados. Houve casos de crianças que somente passaram por uma aval iação oftalmológica ainda quando bebês. Mediante esse quadro e para evitar discrepâncias, assim como fal ta de atual ização dessas informações, foi obtida, junto a uma equipe de médicos oftalmologistas do hospital universitário, uma avaliação oftalmológica de todo o grupo.

A organização dos alunos, ao final de tudo, se baseou num quarto critério, o da faixa etária. Os al unos foram divididos em 3 grupos mistos. Para esse agrupamento não foram levadas em consideração as séries escolares em que se encontravam. O critério de divisão segundo a faixa etária sem essa preocupação permitiu a criação de um ambiente descontraíd o para os al unos, professores epara os desenvolvedores, mesmo à distância. Está claro agora, que de outro modo, o resultado poderia levar à indesejada rotulação do al uno segundo a "competência" formal de cada um, o que certamente causaria desconforto e apreensão, com consequentes reflexos negativos no desempenho deles.

Para os trabal hos a serem realizados pel os alunos junto ao computador, optou-se por oferecer total liberdade no desenvolvimento das atividades propostas. Eles puderam escolher a atividade que mais Ihes aprouvessem realizar. Assim, houvealunos trabal hando com edição detextos, outros navegando pela internet e outros, ainda, brincando com jogos.

Para que os resultados pudessem ser sistematizados, os alunos responderam a questionários nos quais, no geral, deveriam caracterizar o seu uso da ferramenta, explicitando a atividade escolhida para realização e os val ores de configuração aplicados às ampliações que cada um julgou ser adequada. Com vistas a minimizar os efeitos nocivos oriundos ou da total inexperiência do al uno com o uso de recursos computacionais ou mesmo para escapar das estratégias criadas por eles, adquiridas com a intimidade estabelecida com a ferramenta, dois questionários foram preparados e aplicados em dois momentos diferentes dos

\footnotetext{
${ }^{10}$ Tanto o trabal ho de sel eção dos al unos quanto o acompanhamento direto dos testes foram feitos pel os próprios professores das escolas participantes. Assim, não houve da parte da equipe de desenvolvimento qualquer tipo de interferência ou contato mais próximo.
} 
trabal hos. Um deles no início da primeira interação do al uno com a ferramenta eo outro para ser respondido durante uma segunda sessão de trabal ho ${ }^{11}$.

O principal objetivo do primeiro questionário foi obter informações a respeito dos alunos, quais as suas habilidades e quais as suas necessidades mais prementes. Nesse sentido, as informações constantes do primeiro questionário seguiram mais ou menos o seguinte roteiro: identificar os alunos no que tange à sua formação escolar, a experiência com o uso de computadores e a natureza do uso (se faziam) desse equipamento; mapeamento do tipo de comportamento de cada al uno no trabal ho executado com o ampliador. Por comportamento entendaseaqui a configuração escol hida pelo aluno, tais como a fonte preferida para exibição dos caracteres no monitor, o fator de ampliação desejável, a preferência por cores (contraste) e outras características que pudessem ser consideradas de impacto rel evante para o aluno durante a exibição ampliada dos textos/ imagens.

A lém desses objetivos, com esse questionário, a expectativa era a de usar essas informações para realizar uma organização diferente dos alunos para a execução da segunda sessão de avaliação. As informações obtidas, ao contrário, mostraram que cada aluno apresentava necessidades tão peculiares que qual quer tentativa deagrupá-los com base no compartil hamento decaracterísticas não seria algo viável.

Os questionários aplicados na segunda sessão de avaliação, agora disponíveis em mídia, incluíram algumas variantes para as perguntas feitas no primeiro questionário. O objetivo era não apenas tentar confirmar as respostas fornecidas anteriormente pel os al unos, como também avaliar o grau de influência do ambiente de testes, tendo em vista que o primeiro teste aconteceu na universidadee o segundo, nas escolas ondeos al unos estavam habituados a realizar os seus treinamentos com os professores da educação especial ${ }^{12}$.

É importante ressaltar que embora todo o processo de avaliação da ferramenta tenha sido acompanhado pelos membros da equipe de desenvolvimento, coube aos professores dos alunos o trabal ho corpo a corpo. Em todos os sentidos, essa decisão se mostrou acertada e muito bem sucedida. Com eles, os alunos se sentiam mais abertos e aptos para desenvolver as tarefas que Ihes cabiam.

Para essas observações, duas técnicas avaliativas - Think A loud e Talk Aloud (ERICSSON; SIMON, 1993; SOMEREN ; BARNARD; SANDERBERT, 1994) foram utilizadas. Por meio delas, os avaliados são estimul ados a pensar eexpressar

\footnotetext{
${ }^{11}$ O segundo questionário foi aplicado apenas aos alunos que participaram das duas sessões de avaliação. A eles aplicou-se praticamente o mesmo questionário, com pequenas variações. Todavia, as nossas avaliações das respostas fornecidas pelos alunos foram feitas com base na experiência adquirida de cada um deles nas sessões de trabal ho anteriores.

${ }^{12}$ A experiência, embora válida, também não forneceu um resultado expressivo, a ponto de ser considerado nas avaliações.
} 
verbal mente as suas impressões, facilidades e dificuldades com relação às tarefas executadas. Embora não usando instrumentos de gravação deáudio evídeo, como sugerem as técnicas, os aspectos considerados os mais relevantes foram devidamente anotados.

Desse processo de avaliação, tomaram parte 3 pesquisadores, 3 alunos de graduação (bolsistas de IC) e 4 professores da rede pública de ensino, especializados em educação especial/ baixa visão) e que col aboram com o projeto. Da primeira sessão de avaliação participaram 15 alunos, divididos em três subgrupos, conforme os critérios citados anteriormente, assi midentificados: G rupo A ? al unos com até 14 anos de idade (4 al unos); G rupo B ? alunos de 15 a 18 anos (3 alunos) e Grupo C ? acima de 18 anos (8alunos). Essa sessão de testes foi agendada em três ocasiões diferentes. A medida se fez necessária por conta da limitação de computadores e também para evitar aglomerações de alunos e pessoal de observação. A divisão dos al unos em grupos menores permitiu o atendimento ea observação individualizada; logo, mais qual itativa. Cada al uno foi alocado a um computador, cabendo-Ihe, juntamente com o seu professor monitor, decidir o exercício que gostaria de executar, como também já mencionamos antes. Durante a tarefa de preenchimento do primeiro questionário, em razão de os textos não estarem ampliados, foi necessária a intervenção dos monitores no auxílio ao aluno para leitura/ visualização do texto. Esse problema foi resolvido mais tarde (como também já mencionado), na segunda sessão de aval iação.

Tendo em vista a possibilidade de os alunos escolherem o tipo de atividade a executar (edição de textos, navegação na internet, jogos), isso forçou a equipe a um trabal ho de observação mais direcionado; afinal, para muitos alunos, houve a dificuldade natural de manipular os próprios aplicativos escolhidos. Contudo, a natureza do aplicativo em si não causou qual quer prejuízo durante os trabalhos.

N a medida do possível, levando-seem consideração o desempenho de cada aluno, todos executaram as suas tarefas com relativa tranquilidade. Alguns alunos, especialmente aqueles que não tinham experiência com computadores, precisaram de um tempo maior em relação aos outros. Entretanto, uma vez adaptad os ao ambiente, conseguiram avançar satisfatoriamente. A o término dessa primeira seção, cada aluno respondia o primeiro questionário. Os resultados seguem abaixo resumidos:

$\checkmark$ Todos os alunos são usuários de computador há mais de 2 anos, porém, esse uso não ultrapassa 5 anos.

$\checkmark$ Dos 15 alunos, 9 acessam o computador em suas escolas. Os demais têm acesso em suas residências ou em seus ambientes de trabal ho. Contrariando uma expectativa inicial, não houve registro de alunos que fizessem uso de telecentros/ lan-houses, p.ex. 
$\checkmark$ A mai oria dosalunosjá era usuária deTA (lupas eletrônicas, sintetizadores de voz, teclados especiais), motivados por seus professores, pais ou conhecidos ${ }^{13}$. Entretanto, foram identificados al unos que, por falta de conhecimento, nunca tiveram contato com qual quer ferramenta desse tipo.

No que diz respeito ao segundo objetivo com o questionário (identificar os padrões de uso da ferramenta), as seguintes informações puderam ser col etadas:

$\checkmark$ A natureza das atividades escolhidas pel os al unos variou da seguinte forma: no grupo pertencente à faixa etária acima de 18 anos, o computador foi principalmente utilizado para leituras e edições de textos. Entre 15 e 17 anos, os jogos foram as atividades preferidas. Para os al unos abaixo de 15 anos, a preferência por jogos e outros tipos de entretenimentos prevaleceram.

$\checkmark \quad$ O tamanho de fonte mais requisitado pelos alunos ficou em 16 (pontos) ou acima disso, com a maior concentração em fonte detamanho 20 (dos 15 alunos, 10 fizeram essa opção). Quanto ao fator de ampliação, também a maioria optou pel o fator 3.

$\checkmark \quad$ No que se refere ao contraste, a maioria dos al unos disse ter preferência pelo preto ebranco. Contudo, foram registrados casos deal unos quenão conseguiam trabalhar com determinadas cores, inclusive com preto e branco ( 3 alunos). Para esses casos, foi necessário modificar a configuração das cores pelos recursos do sistema operacional do computador, dado que na versão do xL upa que utilizaram, o recurso do contraste ainda não estava disponível. (a atual versão já conta com esse recurso).

Com essas informações em mãos, acrescentado o aspecto do "comportamento dos alunos", foi possível à equipe chegar a algumas conclusões que aqui seguem resumidas. As diferenças apontadas na informação sobre a frequência de uso do computador não apresentaram diferenças expressivas entre aqueles que o usavam diariamente, uma vez por semana ou uma vez por mês. N otou-se um equilíbrio no que tange a essa periodicidade. Ainda em relação a esse tópico, constatou-se que a Internet não foi citada como um recurso muito explorado. Este fato pode ser explicado se levado em conta que os alunos com os quais trabal hamos são provenientes de escolas públicas, localizadas em regiões financeiramentemenos favorecidas (baixo IDH) equepor conseqüência, na maioria das vezes, não têm facilidade de acesso à Internet.

Com base no diagnóstico que pudemos fazer, algumas melhorias foram incorporadas ao xLupa. Uma delas com relação ao cursor. Enquanto na versão inicial, o único cursor disponível ainda era o ponteiro de mouse, na versão sob a avaliação, ao usuário foi dada a opção de escol ha: cursor em ponteiro ou em cruz.

\footnotetext{
${ }^{13}$ Conversas informais com os alunos revelaram que as novidades em relação às ajudas técnicas não estão no centro de suas atenções ou interesses, constatação essa que levou à reflexão acerca dos motivos que esses recursos não chegam àqueles para os quais são projetados.
} 
Como alternativa, decidiu-se também pela fixação ou mobilidade do cursor. Enquanto o cursor fixo atendea determinados usuários, confundea outros. O cursor fixo (não móvel) éum mecanismo que pode auxiliar o indivíduo na determinação do foco. Esse recurso foi anal isado com a devida cautela porque a sua manutenção na ferramenta dependia, antes de tudo, do interesse e da necessidade expressa pelos alunos. Para al guns al unos, tanto o cursor em cruz, quanto a fixação do cursor num determinado ponto da imagem, seja el eem cruz ou como ponteiro, os ajuda, especial mente quando a atividade envolve leitura de textos.

Da segunda sessão de avaliação, dessa feita realizada nas escolas, participaram 9 alunos. Assim como na primeira sessão, as faixas etárias variaram bastante, bem como as condições visuais decada um. Dessa etapa, embora de início tenha sido dito que somente tomariam parte os alunos que tivessem passado pela primeira bateria de testes, de fato, isso não se verificou. $O$ principal motivo é que muitos daqueles alunos acabaram desistindo das escolas, o que nos forçou a uma nova seleção $0^{14}$.

Com relação a essa etapa, convém comentar, as avaliações aconteceram sempre no contra-turno escolar, configurando assim uma atividade de reforço pedagógico. Diferentemente da primeira etapa, nessa, os alunos trabal haram com a ferramenta dentro de um programa regular de atividade escolar, o que garantiu um ambiente mais propício à observação no contexto da educação especial .

Os principais resultados obtidos apontam a regularidade de preferências no uso da ferramenta, tal como detectado nos testes anteriores. $O$ contraste em preto e branco apareceu aqui novamente como uma grande preferência, mas foi também possível constatar que alguns alunos somente conseguiam trabalhar com outros contrastes, que não o preto e branco. Para intensidades de brilho e contraste, um recurso que também não havia na versão inicialmente usada pelos alunos, mas presente na versão utilizada nessa segunda avaliação, foi averiguada uma preferência que, na média, ficou no entorno de $45 \%$ para intensidade do brilho e $55 \%$ para a intensidade do contraste. Dentre as principais críticas e/ ou queixas dos alunos (também dos educadores), citam-se aqui duas, consideradas como as principais, tanto para o primeiro grupo, quanto para o segundo:

$\checkmark$ Quanto à ampliação: a grande maioria deles solicita ampliação em tela inteira e não parcial como na versão atualmenteliberada. Esse recurso já está em fase de conclusão de implementação e testes;

$\checkmark$ Quanto à velocidade do cursor: para alguns dos alunos testados, a não possibilidade de controlar a velocidade do cursor é um problema, uma vez

\footnotetext{
${ }^{14}$ Os alunos novos, para não prejudicar o sistema de avaliação projetado, foram submetidos a uma sessão prévia de trabal ho nas mesmas condições aplicadas aos alunos já iniciados. Dessa maneira, buscamos garantir a consistência e integridade das nossas observações e análises.
} 
que "se perdem" na observação da tela. A solução para esse tipo de problema também já está em fase de conclusão.

\section{Considerações finaIS}

N esse artigo, foram abordados não só os aspectos relacionados com a concepção do xLupa, mas também as suas características funcionais, bem como todo o processo que envolveu a sua construção até o presente momento. Todo o trabal ho de pesquisa se deu a partir de uma metodologia mista, a começar por um estudo comparativo e criterioso envolvendo alguns dos mais importantes ampliadores existentes, tomado como principal referência o Gnopernicus ${ }^{15}$.

A o longo do desenvolvimento desse trabalho, vários obstácul os foram enfrentados, alguns ultrapassados, outros ainda em fase de investigação. No conjunto das possibilidades eresultados obtidos, o quemel hor poderia caracterizar o xLupa, dentre os muitos recursos importantes de que dispõe, é sua capacidade para capturar a tela com rastreamento de mouse, permitindo que o usuário controle o nível de ampliação das imagens, a taxa de tela útil a ser usada para a ampliação, definição do contraste, da intensidade do brilho e ainda do tipo de cursor que melhor se adapte às necessidades do indivíduo. Com a ferramenta, o usuário também écapaz de acionar a leitura de tela, o que pode favorecê-lo especial mente quando precisar ler um texto, quase sempre uma tarefa exaustiva para esse tipo de usuário.

Com base nas avaliações feitas em laboratório e em campo, percebe-se quea ferramenta como um recurso de apoio à educação especial ede promoção de incl usão vem atendendo satisfatoriamente as princi pais necessidades especiais de usuários com baixa visão. O que autoriza essa constatação não são apenas os resultados (positivos) observados, mas também al guns depoimentos (espontâneos) recebidos, tanto da parte dos alunos quanto da dos professores monitores e colaboradores. N esse sentido, o registro mais emblemático equemelhor resumiria tal sensação acontece quando os próprios alunos revelam o fascínio no momento em que descobrem que a ferramenta Ihes permite "enxergar" coisas que, de outra maneira, ainda não Ihes havia sido possível até o contato com ela.

A tualmente, a equipe, além de manter o programa de testes junto aos usuários, investe na melhoria de suas funcionalidades como também na implementação de novos outros recursos. Com vistas a ampliar o universo de usuários, bem como proporcionar melhores condições de trabalhos para eles, algumas parcerias importantes vêm sendo estabel eci das entre a nossa equipe de pesquisa, escolas e outros centros de desenvolvimento tecnológico, a exemplo do Centro de Informação Tecnológica Renato Archer (CTI - Campinas), Associação

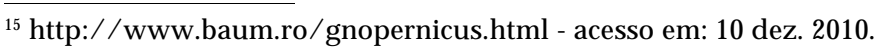


Brasileira de Informática (ABINFO - Campinas/ SP) ePrograma deSoftware Livre (PSL - Curitiba/ PR), que juntos vêm trabal hando na implementação da chamada Carteira Digital, uma solução que agregada ao xLupa, apresenta uma ergonomia mais atrativa e confortável.

\section{REFERÊnCIAS}

BERSCH, R.; TONOLLI, J. C. Tecnologia Assistiva. Disponível em: http:/ / www.assistiva.com.br. A cesso em: 20 dez. 2009.

BUENO, J.G.S. Educação Especial Brasileira: integração/ segregação do aluno diferente. São Paulo: EDUC, 1993.

BIDARRA, J.; BOSCARIOLI, C.; RIZZI, C. B. xLupa - um ampliador de tela com interface adaptativa para pessoas com baixa visão. In: MELO, A. M., PICCOLO, L. S. G., Á VILA, I. M. A, TAMBASCIA, C. A. (Org.). U sabilidade, acessibilidade e inteligibilidade aplicadas em interfaces para analfabetos, idosos e pessoas com deficiência: resultados do workshop. Campinas: CPqD, 2009. p. 23-30.

CHARIN, S. CA POVILLA, F. C. A cesso ao computador por meio deacionadores el etrônicos. Tecnol ogia em (Re) habilitação C ognitiva: a dinâmica clínica-teoria-pesquisa. São Paulo: Centro Universitário São Camilo, 2000.p. 169-174.

COLEM BRANDER, A. Reabilitação de baixa visão. In:VEIZTMAN, S. (Ed.). V isão Subnormal. Rio de Janeiro: Cultura Médica, 2000.

COOK, A. M.; POLGAR, J. M.; HUSSEY, J. M. Cook and Hussey's A ssistive Technologies: principles and practice. Mosby: Year book, inc., 1995.

KOON, R.; VEGA, M. E. El impacto tecnológico en las personas com discapacidad, 2000. Disponível em: www.f-integra.org/ tecnoneet.ponentes.htm A cesso em: 29 jun. 2010.

ERICSSON, K.; SIMON, H. Protocol A nalysis: verbal reports as data. 2. ed. Boston: MIT Press, 1993.

GUIMARÃES, L. A cor como informação: a construção biofísica, lingüística e cultural da simbologia das cores. São Paulo: A nnablume, 2003.

HOGETOP, L.; SANTAROSA, L. M. C. Tecnologias Assistivas: viabilizando a acessibilidade ao potencial individual. PGIE-U FRGS - Informática na educação: teoria e prática, Porto A legre, v. 5, n. 2, nov. 2002.

JACOBSON, N .; BENDER, W. Color as a determined communication. IBM Systems J ournal. M IT M edia Lab, v. 35, n. 3/ 4. 1996.

LAWRENCE, A.; VANDERHEIDEN, G. C. Consideration in the design of computers and operating systems to increase their accessibility to persons with disabilities. USA: Madison, 1998.

PASCHOAL, C. L. L. Educação visual. Monografia de Especialização, Curso de Especial ização de Professores na área da Deficiência Visual, Instituto Benjamin Constant, Rio de Janeiro, 1993. 
RODNEY, P. El aspecto psicológico de la discapacidad visual como elemento de compreensión em el desarollo de la inclusión. Entre dos mundos, revista de traducción sobre discapacidad visual, Madrid, n. 22, 2003.

SANTAROSA, L. M.C. Simulador de teclado para portadores de paralisia cerebral: avaliação e adaptação para Português. In: CYTED ACCIONES DE COOPERACIÓN EM CIENCIA Y TECN OLOGIA COM INCIDENCIA EM LA MEJORA DE LA CALIDAD DE VIDA DE LA INFANCIA Y LA ADOLESCEN CIA IBEROA MERICANAS, 2000, Madrid, AlabaS/ A, V.I, p.31-40.

Escola Virtual para a Educação Especial: ambientes de aprendizagem telemáticos cooperativos como alternativa de desenvolvimentos. Revista de Informática Educativa, Bogotá/ Colômbia, UNIDA DES, v. 10, n.1, p. 115-138, 1997.

SANTAROSA, L.M.C.; MA RTINS, A. Simulador de teclado: Versão 1.0. Manual do Usuário. Porto A legre: Editora da UFRGS, 1995.

SOMEREN, M.W.; BARNARD, Y.F.; SANDBERG, J.A.C. The think al oud method - A practical guide to modelling cognitive processes. Department of Social Science Informatics University of Amsterdam. London: A cademic Press, 1994.

SOUZA, C. et al. Projeto de Interfaces de Usuários: perspectivas cognitivas e semióticas. A postila do Curso de Projeto de Interfaces de U suário - D epartamento de Informática, Rio de Janeiro: PUC, 1999.

VANDERHEIDEN, G.C.; VANDERHEIDEN, K.R. Accessible design of consumer products. Guidelines for the design of consumer products to increase their accessibility to the people with disabilities or who are aging. USA: Center at the University of Wisconsin, 1991.

Recebido: 14/ 09/ 2010

Reformulado: 01/ 03/ 2011

A provado: 04/ 04/ 2011 
BIDARRA, J.; BOSCARIOLI, C.; PERES, S. M. 